\title{
LETTER
}

\section{CRYSTMAS study adds to concerns about renal safety and increased mortality in sepsis patients}

\author{
Christiane S Hartog and Konrad Reinhart* \\ See related research by Guidet et al., http://ccforum.com/content/16/3/R94
}

The CRYSTMAS trial compared resuscitation fluids 6\% HES $130 / 0.4$ and $0.9 \% \mathrm{NaCl}$ in patients with severe sepsis to fulfil a postmarketing study commitment issued by the US Food and Drug Administration (FDA). However, published trial outcomes were selective. When the more complete data set is assessed and compared against previous data, it rather suggests that use of HES 130/0.4 does not lead to clinically relevant volume savings, and suggests similar negative effects on kidney function as were seen with an older HES solution and an increase in 90-day mortality by $6.8 \%$.

The CRYSTMAS trial by Guidet and colleagues [1] lacked power to address renal safety [2]. However, observed outcomes add to existing safety concerns [3]. The number of subjects undergoing renal replacement therapy (RRT) doubled in the hydroxyethylstarch (HES 130/0.4) arm [4] (Table 1); mean duration of RRT was 9.1 days versus 4.3 days [4]; and Kaplan-Meier curves for time to RRT showed a trend against HES $(P=0.06$; Figure 1) [4]. Serious adverse events and serious adverse events leading to death numbered 53 versus 44 and 38 versus 32, respectively (HES versus saline) [4]. Mortality rates were all higher in the HES arm, and 90-day mortality rates were remarkably similar compared to a previous sepsis trial with 10\% HES 200/0.5 [3] (Figure 2). These study data were not published in the journal article. Withholding data from original publications - socalled publication bias - is a major problem [5]. There was also other reporting bias. The primary outcome required fluid volumes - was only reported for a post hoc subgroup of patients who reached hemodynamic stabilisation (174 of all 196 patients), misleadingly called the 'full analysis set'. The numbers of patients available for safety outcomes was inconsistent. Publication and reporting bias can lead to overestimation of the treatment effect and underestimation of safety risks [5].

Our reading of the extended CRYSTMAS study data therefore leads to somewhat changed key messages: use of HES 130/0.4 does not lead to clinically relevant volume savings; and negative effects on kidney function and mortality after HES $130 / 0.4$ were similar to those seen after an older HES solution.

Table 1. Comparison of outcome data from two multicenter RCTs and patients with severe sepsis

\begin{tabular}{|c|c|c|c|c|c|c|}
\hline & \multicolumn{3}{|c|}{ CRYSTMAS } & \multicolumn{3}{|c|}{ VISEP [3] } \\
\hline & $\begin{array}{l}\text { Percentage } 6 \% \\
\text { HES } 130(\mathrm{n} / \mathrm{N})\end{array}$ & $\begin{array}{c}\text { Percentage } \\
\text { crystalloid (n/N) }\end{array}$ & $P$-value & $\begin{array}{l}\text { Percentage } 10 \% \\
\text { HES } 200(n / N)\end{array}$ & $\begin{array}{c}\text { Percentage } \\
\text { crystalloid }(\mathrm{n} / \mathrm{N})\end{array}$ & $P$-value \\
\hline \multicolumn{7}{|c|}{ New need for RRT } \\
\hline 7-day & 17 patients $^{\mathrm{a}}$ & 8 patients $^{\mathrm{a}}$ & & & & \\
\hline 28-day & & & & $31(81 / 261)$ & $18.8(51 / 272)$ & 0.001 \\
\hline 90-day & 21 patients $^{\mathrm{a}}$ & 11 patients $^{\mathrm{a}}$ & & & & \\
\hline \multicolumn{7}{|l|}{ ARF } \\
\hline 28-day & & & & $34.9(91 / 261)$ & $22.8(62 / 272)$ & 0.002 \\
\hline 90-day & $24.5(24 / 98)^{b}$ & $20(19 / 95)^{b}$ & 0.45 & & & \\
\hline \multicolumn{7}{|l|}{ Mortality } \\
\hline 28-day & $31.0(31 / 100)^{c}$ & $25.3 \%(24 / 95)^{c}$ & 0.37 & $26.7(70 / 262)$ & $24.1(66 / 274)$ & 0.48 \\
\hline 90-day & $40.4(40 / 99)^{c}$ & $33.6(32 / 95)^{c}$ & 0.33 & $33.9(93 / 274)$ & $41.0(107 / 261)$ & 0.09 \\
\hline
\end{tabular}

${ }^{a}$ Data according to [4]; total number of patients with available data is not given. ${ }^{b}$ Data according to $[1,6]$. 'Data according to [1]. $\mathrm{n}=\mathrm{number}$ of patients with condition; $\mathrm{N}=$ total number of patients with available data. ARF, acute renal failure; RRT, renal replacement therapy. 


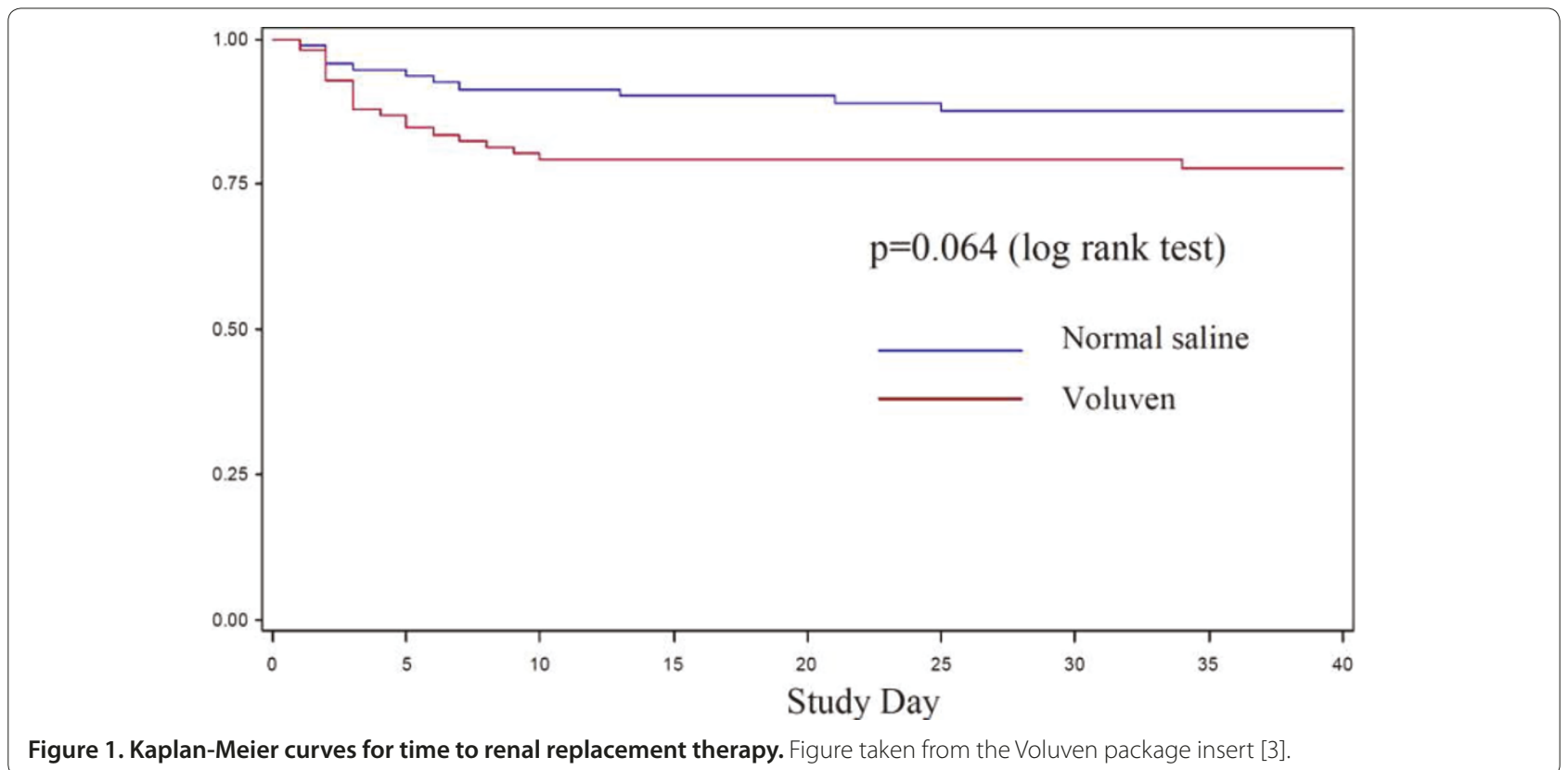

Figure 1. Kaplan-Meier curves for time to renal replacement therapy. Figure taken from the Voluven package insert [3].

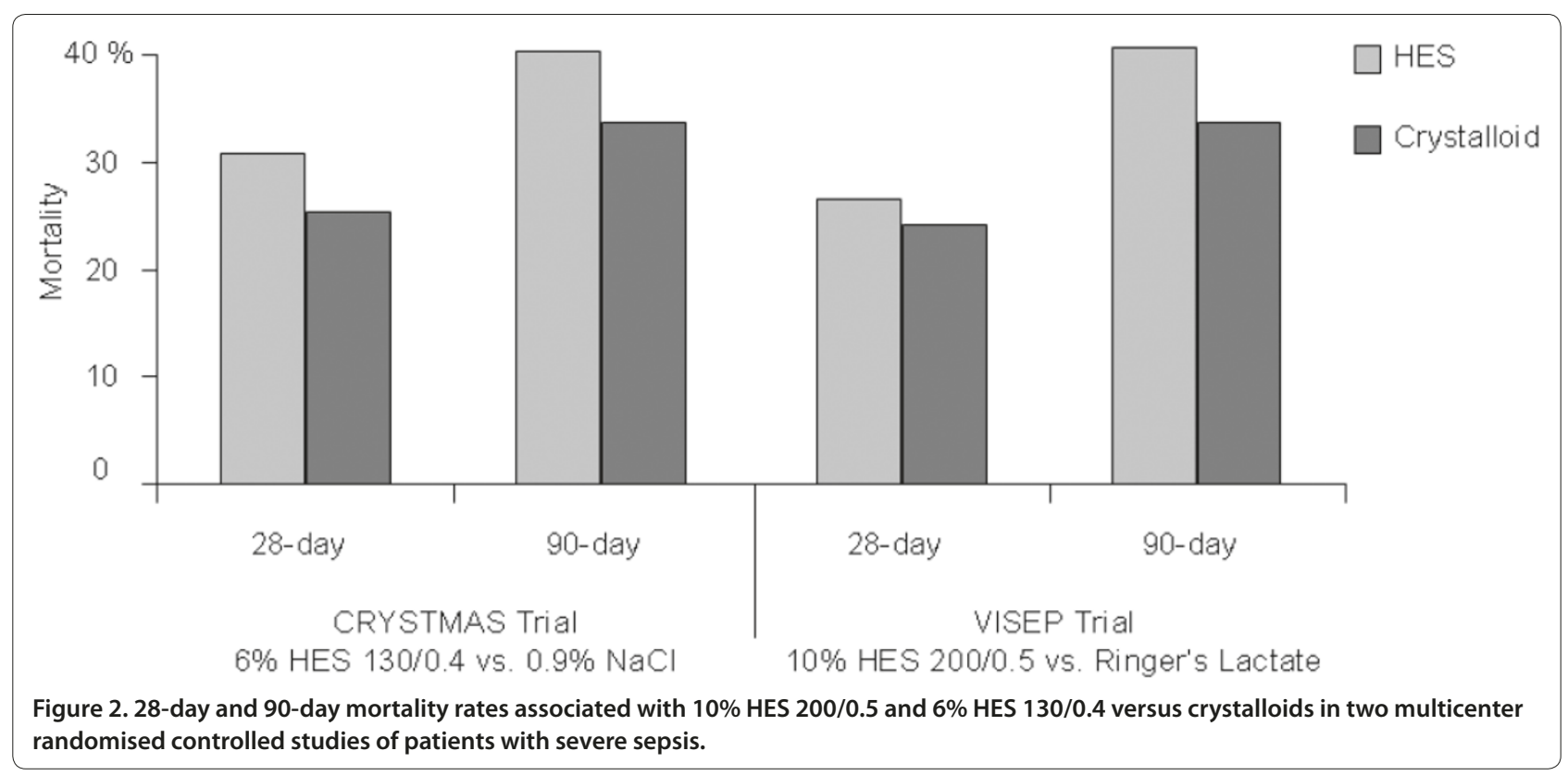

\section{Authors' response}

Bertrand Guidet and Hugo van Aken

We appreciate the opportunity to clarify the inappropriate statements by Hartog and Reinhart. The manuscript was based on the results of the Clinical Study Report, which reflected defined statistical analysis plan (SAP) analyses prospectively agreed with the FDA, and was accepted for publication on 20 March 2012. Thus, the primary endpoint still holds true and is not a post hoc analysis.

Concomitantly and independently, the FDA requested additional, unplanned post hoc analyses by the sponsor
Fresenius Kabi, which were finally agreed upon on 7 May 2012. At this stage, the manuscript had already been accepted for publication.

Therefore, the Kaplan-Meier for time to RRT was newly created and confirms that the study was too small to investigate this parameter. Notably, internationally accepted scores of kidney injury are all presented in the paper, and the use of RRT is reflected by the Acute Kidney Injury Network (AKIN) criteria. 


\section{Abbreviations}

FDA, US Food and Drug Administration; HES, hydroxyethylstarch; RRT, renal replacement therapy.

\section{Competing interests}

$\mathrm{CSH}$ declares no conflict of interest. KR has received an unrestricted research grant for the conduct of the VISEP trial and consultancy fees from B Braun Melsungen

Published: 7 November 2012

\section{References}

1. Guidet B, Martinet O, Boulain T, Philippart F, Poussel JF, Maizel J, Forceville X, Feissel M, Hasselmann M, Heininger A, Van Aken H: Assessment of hemodynamic efficacy and safety of $6 \%$ hydroxyethylstarch $130 / 0.4$ vs. $0.9 \% \mathrm{NaCl}$ fluid replacement in patients with severe sepsis: The CRYSTMAS study. Crit Care 2012, 16:R94.

2. Perner A, Haase N, Wetterslev J, Aneman A, Tenhunen J, Guttormsen AB, Klemenzson G, Pott F, Bødker KD, Bådstøløkken PM, Bendtsen A, Søe-Jensen P, Tousi H, Bestle M, Pawlowicz M, Winding R, Bülow HH, Kancir C, Steensen M, Nielsen J, Fogh B, Madsen KR, Larsen NH, Carlsson M, Wiis J, Petersen JA, Iversen S, Schøidt O, Leivdal S, Berezowicz P, et al.: Comparing the effect of hydroxyethyl starch 130/0.4 with balanced crystalloid solution on mortality and kidney failure in patients with severe sepsis (6S Scandinavian Starch for Severe Sepsis/Septic Shock trial): study protocol, design and rationale for a double-blinded, randomised clinical trial. Trials 2011, 12:24.

3. Brunkhorst FM, Engel C, Bloos F, Meier-Hellmann A, Ragaller M, Weiler N, Moerer O, Gruendling M, Oppert M, Grond S, Olthoff D, Jaschinski U, John S, Rossaint R, Welte T, Schaefer M, Kern P, Kuhnt E, Kiehntopf M, Hartog C, Natanson C, Loeffler M, Reinhart K; German Competence Network Sepsis (SepNet): Intensive insulin therapy and pentastarch resuscitation in severe sepsis. N Engl J Med 2008, 358:125-139.

4. Package insert Voluven [http://www.fda.gov/downloads/ BiologicsBloodVaccines/BloodBloodProducts/ApprovedProducts/ NewDrugApplicationsNDAs/UCM083138.pdf]

5. McGauran N, Wieseler B, Kreis J, Schuler YB, Kolsch H, Kaiser T: Reporting bias in medical research - a narrative review. Trials 2012, 11:37.

6. Effects of Voluven on Hemodynamics and Tolerability of Enteral Nutrition in Patients With Severe Sepsis (CRYSTMAS). NLM Identifier: NCT00464204 [http://clinicaltrials.gov/ct2/show/study/NCT00464204?sect=Xji8015]

doi:10.1186/cc11673

Cite this article as: Hartog CS, Reinhart K: CRYSTMAS study adds to concerns about renal safety and increased mortality in sepsis patients. Critical Care 2012, 16:454 